\title{
Asset pricing in small markets - the South African case
}

\author{
D.J. Bradfield ${ }^{*}$ and G.D.I. Barr \\ Department of Mathematical Statistics, University of Cape Town, Rondebosch, 7700 Republic of South Africa
}

\author{
J.F. Affleck-Graves
}

Department of Finance and Business Economics, University of Notre Dame Notre Dame, Indiana 46556

Received 1 September 1987; Accepted 14 September 1987

\begin{abstract}
The authors examine the validity of the CAPM for Johannesburg Stock Exchange (JSE) stocks. Additional effects, namely, dividend yield, size and liquidity are also considered using traditional tests. The results indicate that the one-parameter CAPM is well-specified for the JSE. The betas of gold shares, however, are found to be poor predictors of rand returns - but improve when viewed in dollar terms. None of the abovementioned effects are found to be significant, however, a slight preference for high-yielding gold shares is documented. Explanations for these findings are offered and contrasted with results documented on the NYSE.
\end{abstract}

Dic geldigheid van die sogenaamde 'CAPM'-model vir die Johannesburgse Effektebeurs word ondersoek. Addisionele faktore, soos dividendopbrengs, grootte van maatskappy en likwiditeit word deur middel van tradisionele toetse in ag geneem. Resultate dui aan dat die een-parameter-'CAPM toepaslik is op die Johannesburgse Effektebeurs. Die beta-waardes van goudaandele is egter swak voorspellers van opbrengs in randterme, maar verbeter wanneer die dollarterme beskou word. Geen een van die bogenoemde faktore is betckenisvol nie, maar 'n neiging tot voorkeur vir goudaandele met 'n hoë dividendopbrengs word aangedui. Verduidelikings vir hierdie bevindinge word voorgestel en vergelyk met ooreenstemmende resultate op die New Yorkse Effektebeurs.

* To whom correspondence should be addressed

Markowitz (1952) developed the first major normative theory of portfolio selection. Although this development was a significant milestone in Financial Economics, the theory did not directly help to explain the manner in which individual assets would be priced in the market. However, using the Markowitz portfolio selection approach, Sharpe (1964) and Lintner(1965) independently developed a positive theory of asset pricing. Many generalizations of the theory followed with Mossin's (1966) contribution being probably the most significant. As a result the model is frequently referred to as the Sharpe-Lintner-Mossin Capital Asset Pricing Model or more simply as CAPM.

The CAPM can be written as

$E\left(R_{i}\right)=r_{f}+\beta_{i}\left[E\left(R_{m}\right)-r_{f}\right]$

where $E\left(R_{i}\right)=$ the expected return on the $i$ th security; $E\left(R_{m}\right)=$ the expected return on the market of all assets; $r_{f}=$ the risk-free rate; and $\beta_{i}=$ covariance $\left(R_{i} ; R_{m}\right) /$ variance $\left(R_{m}\right)$.

The most important implication of this model is that investors can only expect to be compensated for bearing systematic or market-related risk (i.e. covariance $\left(R_{i}\right.$; $R_{m}$ ). Consequently any unsystematic or firm-specific risk will not be priced in the market for all assets. Clearly, if true, the CAPM has important implications for both individual firms and investors. As a result, it has been the focus of much empirical research.

Most of the empirical tests of the CAPM have been conducted using data from the major American exchanges - the New York Stock Exchange (NYSE), the American Stock Exchange and the NASDAQ Overthe-counter Markets. Some of these have attempted to test the CAPM directly whilst others have investigated whether additional factors are relevant for asset pricing. In particular, factors such as dividend yield, market capitalization, price-earnings ratios, and January effects have all been empirically tested for evidence that may promise the investor consistent excess returns over the market.(See for example Black \& Scholes, 1974, Banz, 1981, Basu, 1977 and Reinganum, 1983 respectively.)

Despite the considerable efforts to empirically test the CAPM in the American environment, relatively little attention has been paid to smaller exchanges such as the Johannesburg Stock Exchange (JSE). Because the assumptions on which the CAPM is based include, inter alia, market efficiency and the absence of transaction costs (Jacob \& Pettit, 1984), it is not obvious that the American results are directly translatable from the NYSE to the JSE. Therefore in this paper the CAPM will be examined in the context of the JSE. The first section of the paper consists of a brief review of the results of the relevant studies concerning the validity of the CAPM. As mentioned almost all of these studies have used the NYSE as the testing ground.

In the second section JSE stocks will be under scrutiny. Initially the one-parameter CAPM will be empirically examined. Thereafter several additional parameters, namely dividend yield, market capitalization and liquidity will be empirically examined to determine whether they have any significant additional influence on returns of JSE stocks. Traditional tests in the CAPM framework will be 
conducted for each of the factors. As gold share behaviour is of particular interest in the JSE context this sector will be tested separately.

\section{Review of results}

In the early 1970 s most relevant studies found general support for the CAPM. The prominent studies were those of Black, Jensen \& Scholes (1972), Blume \& Friend (1973) and Fama \& Macbeth (1973). However, Roll (1977) raised several pertinent questions relating to the validity of the empirical tests used to test the CAPM. In particular, Roll argued that any test of the CAPM was in fact a joint test of both the CAPM and the suitability of the index used as a surrogate for the market portfolio. Consequently, rejection of the null hypothesis does not necessarily imply rejection of the CAPM.

Stambaugh (1982) addressed this issue by constructing broader market indices which include bonds and real estate. He concluded that the tests did not appear to be very sensitive to the choice of the market proxy'.

Other researchers meanwhile have concentrated on the assumptions underlying the CAPM and have developed extensions of the model under relaxed assumptions. For example, Mayers (1972) has considered a model which incorporates the existence of nonmarketable assets such as human capital. Merton (1973) has derived a version of the CAPM which assumes trading takes place continuously over time, and that asset returns are distributed lognormally. Brennan (1970) and Litzenberger \& Ramaswamy (1979) have considered models which include the effect of differential tax rates on capital gains and dividends.

Recent attention has, however, been focused on whether additional explanatory factors are relevant in assset pricing models. Since this issue represents the central theme of this paper it will be instructive to consider some of the previous studies on this topic. The methodology used in these studies follows the wellknown testing procedures of Fama \& Macbeth (1973) and Black \& Scholes (1974). Essentially this technique involves cross-sectional regressions of asset returns on estimated beta coefficients and hypothesized additional explanatory factors. Estimates of the resulting coefficients are interpreted. Often the data are grouped to reduce measurement errors and in some studies the estimation is done at a sequence of time points. This creates a time series of estimates from which the precision of the overall average can be determined.

\section{Dividend yield effects}

The controversy surrounding dividend yield effects stems from the effect of differential tax rates on capital gains and dividends. Because dividends are generally more heavily taxed than capital gains the question arises of whether an investor who 'tilts' his portfolio towards low yield securities is increasing or decreasing his expected after-tax return arises. Brennan (1970) and Litzenberger \& Ramaswamy (1979) argue that the higher a stock's dividend yield, the higher the pre-tax return a taxable investor requires to compensate for the tax liability incurred (holding risk constant). Miller \& Scholes (1978) however, present a counter argument whereby investors can effectively transform dividend income into capital gains. For example, sufficient leverage of an equity portfolio can create interest expenses that can be used to offset the dividend income entirely. Further, any unwanted risk in this levered position can be removed by the purchase of whole life insurance which contains a tax-deferred investment component. They therefore argue that if investors are using these or similar tax shelters then the pre-tax rate of return on dividend paying stocks may not differ from the rate of return on stocks paying no dividends at all. This implies that the tax exempt institutions that shift their portfolios towards high-yielding stocks do not enjoy the benefits of higher pre-tax returns.

Black \& Scholes (1974) pioneered the empirical testing of the effects of dividend yield on common stock return. Their test involved the addition of a dividend payout term in the empirical version of the CAPM

$R_{j}=\gamma_{0}+\gamma_{1} \beta_{j}+\gamma_{2}\left(\delta_{j}-\delta_{m}\right) / \delta_{m}+\epsilon_{j}$

where $R_{j}$ is the rate of return on the $j$ th portfolio; $\gamma_{0}$ is an intercept term which should be equal to the risk-free rate, $r_{f}$, according to the CAPM; $\gamma_{1}$ is the expected market premium, according to the CAPM; $\beta_{j}$ is the systematic risk of the $j$ th portfolio; $\gamma_{2}$ is the additional factor effect coefficient (i.e. the dividend yield effect coefficient here); $\boldsymbol{\delta}_{j}$ is the additional factor measure of the $j$ th portfolio (i.e. the dividend yield of the $j$ th portfolio here), $\delta_{m}$ is the additional factor measure of the market portfolio, (i.e. the dividend yield of the market here), $\epsilon_{j}$ is the error term.

The results of Black \& Scholes (1974) are summarized in Table 1.

On the basis of Table 1 Black \& Scholes conclude that over the entire period as well as for every sub-period under study the estimate of $\gamma_{2}$ is not significantly different from zero. This implies that the expected returns on high-yielding securities are not significantly different from the expected returns on low-yielding securities for the same level of risk. Note that a significantly negative value for $\gamma_{2}$ implies that highyielding stocks have lower expected returns than lowyielding stocks of equal risk. This in turn implies a

Table 1 Results of the Black-Scholes test for dividend effects

\begin{tabular}{lll}
\hline Period & $\alpha_{2}=\hat{\gamma}_{2}$ & $t\left(\alpha_{2}\right)$ \\
\hline $1936-66$ & 0,0009 & 0,94 \\
$1947-66$ & 0,0009 & 0,90 \\
$1936-46$ & 0,0011 & 0,54 \\
$1947-56$ & 0,0002 & 0,19 \\
$1957-66$ & 0,0016 & 0,99 \\
$1940-45$ & 0,0018 & 0,34 \\
\hline
\end{tabular}


preference for high-yielding stocks on the part of investors. Alternatively a significantly positive value for $\gamma_{2}$ would imply an aversion for dividends on the part of investors.

Several other researchers have continued to sift through the data in the hope of unearthing evidence to reveal why so important a tax penalty on dividends should have left so small a trace in the data. Among these researchers are Long (1978), Litzenberger \& Ramaswamy (1979), (1980), (1982), Rosenberg \& Marathe (1979), Stone \& Bartter (1979), Blume (1980), Gordon \& Bradford (1980), Miller \& Scholes (1982) and Keim (1985). While many of the above researchers do uncover evidence of a positive significant dividend yield effect, they do not, in general attribute the significant yield effects to taxes. Rather it is suggested that other anomalies such as the size effect (discussed below) may interact with the dividend yield effect.

\section{The size effect}

Several recent studies on the NYSE have documented evidence of a significanrt relation between common stock returns and the market value of common stock. This has become known as the 'size effect'. Banz (1981) was one of the first to investigate this relationship. His study was similar in spirit to that of Black \& Scholes (1974). The empirical form of the CAPM with the additional factor shown in equation (1) was also used. For the $\delta_{j}$ in (1) Banz used the market value of security $j$ and for the $\delta_{m}$ he used the average market value. The time series of gammas obtained from the cross-sectional regressions using (1) were also regressed on the excess returns of the market index to obtain the final estimators. Table 2 shows a summary of the results obtained by Banz (1981).

From Table 2 it is evident that all signs of the $\hat{\gamma}_{2}$ 's (i.e. the size factors) are negative and most of these coefficients are significant. Banz (1981) therefore finds a negative statistical association between returns and firm size. This clearly implies that shares of firms with large market values have had smaller returns on average than small firms in similar risk classes.

Reinganum (1981), using a different method over the period 1963-1977, also found that portfolios of small firms had higher risk-adjusted returns than portfolios of

Table 2 Results of the Banz study for size effects

\begin{tabular}{lcc}
\hline Period & $\hat{\gamma}_{2}$ & $t\left(\hat{\gamma}_{2}\right)$ \\
\hline $1936-75$ & $-0,00052$ & $-2,92$ \\
$1936-55$ & $-0,00043$ & $-2,12$ \\
$1956-75$ & $-0,00062$ & $-2,09$ \\
$1936-45$ & $-0,00075$ & $-2,32$ \\
$1946-55$ & $-0,00015$ & -0.65 \\
$1956-65$ & $-0,00039$ & $-1,27$ \\
$1966-75$ & $-0,00080$ & $-1,55$ \\
\hline
\end{tabular}

larger firms. Blume \& Stambaugh (1983) however, show that the technique used in Reinganums study produces an upward bias on estimates of small-firm portfolio returns owing to 'bid-ask' bias that is inversely related to firm size. They show that avoidance of this bias results in the size premium being halved. It is still not clear whether size per se is responsible for the effect or whether size is just a proxy for some factor correlated with size.

\section{The liquidity effect}

One may well expect the size effect to be related to a liquidity effect in that the smaller the firm the less liquid the stock is expected to be. Chi-Cheng, Reilly \& Wong (1985) give empirical evidence in support of the above statement. They suggest that liquidity could be one of the missing factors in the CAPM because of the close relation between the size and liquidity effects. An issue of interest therefore is to determine to what extent, if any, the liquidity of a capital asset affects its pricing structure.

While the concept of liquidity is straightforward the problem of finding a suitable measure of liquidity that the practitioner can easily apply is not. Several measures of liquidity have been used by the financial community. These measures are usually formulated as ratios of asset price changes to trading volume changes. The main shortfall of measuring liquidity in this way is that asset price changes not only reflect the liquidity effect but also reflect changes that occur owing to the arrival of new information, thus biasing measures of this type. Tinic (1972) suggests the use of the bid-ask spread as a proxy for liquidity. He justifies its use by saying:" Since specialists supply liquidity (illiquidity) service under conditions of uncertainty, the difference between the bid and the ask prices, twice the specialists price for supplying liquidity. must not represent not only the technical efficiency of inventory management but also the extent of the prevailing risks and the ability of the dealer to assume these risks.'

Very little empirical evidence concerning tests of the liquidity effect on stock return has been documented to date. In a recent paper by Amihud \& Mendelson (1986) empirical evidence was found which indicates that liquidity (the bid-ask spread) is significantly related to return in the CAPM framework. The implication of this finding is that investors should require a higher expected return for less liquid stocks in order to compensate them for the higher cost of trading. That is, the price of less liquid assets should be bid down in order to yield higher returns. Furthermore, because the cost associated with the bid-ask spread has to be borne only once over a holding period, investors will tend to hold high-spread stocks for longer periods. Investors with shorter holding periods will be willing to pay more to acquire the lowspread securities. Real estate or stamps for example have after-comission returns too low for short-term holding, but may provide superior performance over longer periods. This suggests the existence of liquidity 
'clienteles' for the various assets. Long-term investors for example may prefer more illiquid assets provided they promise higher returns.

\section{The JSE under scrutiny}

In this section the applicability of the CAPM for JSE stocks will be empirically investigated. The three additional factors reviewed above, namely dividend yield, market capitalization and liquidity effects will thereafter be tested in the context of the JSE. In addition, owing to the unique nature of the gold share market, gold shares will be tested separately under each of the above headings.

\section{Methodology}

The empirical tests used in the remainder of this paper are based on the well-known testing procedure of Black \& Scholes (1974), where expected return is modelled as a linear function of the market risk, $\beta$, with an additional factor $\delta$ representing the effect being investigated.. This model is shown in (1). The approach adopted involves splitting the data into three separate time periods. Data in the first time period are used to group the individual securities into portfolios on the basis of the additional factor and the security beta. The relevant parameters of the portfolios are then estimated using data from the second period. Finally crosssectional regressions are run on data from the third time period.

The empirical analog of equation (1) is thus

$R_{p t}=\gamma_{01}+\gamma_{1 t} \hat{\boldsymbol{\beta}}_{p, t-1}+\gamma_{2 t}\left[\frac{\hat{\delta}_{p, t-1}-\hat{\delta}_{m, t-1}}{\hat{\boldsymbol{\delta}}_{m, t-1}}\right]$

The specifics of the approach are as follows:

The securities are assigned to one of 20 portfolios containing a similar number of securities as follows. Firstly the securities are ranked according to their estimates of the additional factor and divided into four groups. Thereafter each group is further subdivided into five portfolios on the basis of their ranked $\beta s^{2}$. Four years' data are used for the initial estimation of $\beta$ 's and additional factor measures for the construction of the portfolios. The next four years' data are used to reestimate these statistics for the 20 portfolios. The crosssectional regression (2) is then performed at each fourweek period of the subsequent year. Thus 13 crosssectional regressions were performed in each testing period of one year.

In order to help remove the effects of interpreting market-induced positive and negative $\hat{\gamma}_{i, t}$ for the series of cross-sectional regressions, the widely used technique suggested by Black \& Scholes (1974) of regressing the time series of gammas on the excess return of the market is used. This correction involves running the following time series regression in each testing period

$\hat{\gamma}_{2, t}=\alpha_{2}+\eta_{2}\left(R_{m, t}-r_{f, t}\right)$
Table 3 Data periods

\begin{tabular}{lccccc}
\hline & \multicolumn{5}{c}{ Period } \\
\cline { 2 - 6 } & 1 & 2 & 3 & 4 & 5 \\
\hline Portfolio formation period & $1973-75$ & $1973-76$ & $1974-77$ & $1975-78$ & $1976-79$ \\
Initial estimation period & $1976-79$ & $1977-80$ & $1978-81$ & $1979-82$ & $1980-83$ \\
Testing period & 1980 & 1981 & 1982 & 1983 & 1984 \\
\hline
\end{tabular}

where $R_{m, t}$ is the return on the market at time $t ; r_{f, i}$ is the risk-free rate; $\eta_{2}$ is the slope coefficient. The $\hat{\alpha}_{2}$ is then interpreted as the final estimator for $\hat{\gamma}_{2}$.

\section{The data}

A sample of 100 stocks listed on the JSE was chosen using a systematic sampling technique to ensure that no sector or well-traded security was favoured in the selection procedure. The extracted data consisted of weekly prices from 1 January 1973 to 31 December 1984. Only securities having a record of prices for 1973 through to 1984 were considered for selection. A series of returns taken at four-week intervals was then used for the study.

For the tests on gold shares all available gold shares having a series of prices over the period of study were used. The JSE Actuaries Overall Index and the All-Gold Index were used to proxy the 'market', while the 12 month fixed deposit rate at major commercial banks was used to proxy the risk-free rate.

Table 3 below shows the breakdown of the time periods used in the empirical tests.

\section{Empirical results}

\section{The one-parameter CAPM}

The JSE as a whole

The one-parameter CAPM tests were conducted on the systematic sample of 100 stocks. The model posits a positive relation between expected stock return and market risk, beta, and hence for these tests the $\gamma_{2}$ term in equation (2) is set equal to zero in the cross-sectional regressions of the beta-sorted portfolios. Otherwise the methodology is identical to that described above.

The results of the tests that $\gamma_{1}$ is not significantly different from the market premium and that $\gamma_{0}$ is not significantly different from the risk-free rate are summarized in Table 4 .

Table 4 The JSE as a whole

\begin{tabular}{lccccc}
\hline Period & $\overline{\hat{\gamma}_{a}-r_{f}}$ & $t \overline{\left(\hat{\gamma}_{0}-r_{f}\right)}$ & $\overline{\hat{\gamma}_{1}-\left(R_{m}-r_{f}\right)}$ & $t\left(\overline{\hat{\gamma}_{1}-\left(R_{m}-r_{f}\right)}\right)$ & $\bar{R}^{2}$ \\
\hline $1973-80$ & 0,0074 & 0,699 & $-0,0042$ & $-0,393$ & 0,234 \\
$1973-81$ & 0,0229 & 1,467 & $-0,0148$ & $-0,885$ & 0,166 \\
$1974-82$ & $-0,0247$ & $-1,259$ & 0,0239 & 1,025 & 0,305 \\
$1975-83$ & 0,0093 & 0,581 & 0,0032 & 0,212 & 0,218 \\
$1976-84$ & 0,0008 & 0,030 & $-0,0052$ & $-0,197$ & 0,249 \\
\hline
\end{tabular}


Columns 2 and 4 show the resulting coefficients minus their hypothesized value averaged over each testing period. The coefficients are obtained from the crosssectional regressions in each month whilst the subtracted values (i.e. the $r_{f}$ and $R_{m}-r_{f}$ ) are the actual realized risk free ratte and market premiums respectively in each corresponding month. Under the null hypothesis these values are expected to be equal to zero ${ }^{3}$.

Inspection of the $t$ statistics in Table 4 show that for all five periods none of the $t$ statistics are statistically significant at the $5 \%$ level. This implies that the $\gamma_{1}$ of equation (1) is not significantly different from the market premium. Similarly, the $\gamma_{0}$ in (1) is not significantly different from the risk-free rate. The abovementioned evidence gives support to the validity of the one-parameter CAPM for JSE stocks.

The above conclusion regarding the slope coefficient (i.e. $\left.\gamma_{1}\right)$ is similar to that reached in many of the U.S. studies (e.g. Fama \& Macbeth, 1973). However, it is worth noting that the results for the intercept term (i.e. $\gamma_{0}$ ) differ somewhat from those of Banz (1981) who obtained a value of 0,0045 for $\overline{\gamma_{0}-r_{f}}$ with an associated $t$ value of 2,76 for the 1936-1975 period on the NYSE. He concluded that $\gamma_{0}$ was different from the assumed riskfree rate namely the three-month U.S. Treasury Bill (T.B.) rate. Black, Jensen \& Scholes (1972) and Black $\&$ Scholes (1974) also found evidence on the NYSE that the intercept term in the CAPM is different from the U.S. three-month T.B. rate. However, they argue that $\gamma_{0}$ is still an appropriate risk-free rate, namely the expected return on a zero beta portfolio, but that this is different from the three-month T.B. rate.

Further insight surrounding the linear relationship between return and beta posited by the CAPM can be found by considering the regressions of the time series of $\hat{\gamma}_{1}$ 's on the market premium. This widely used technique suggested by Black \& Scholes (1974) is thus similar to the one described in the methodology section except that the dependent variable in this instance is the $\gamma_{1}$ here, i.e.

$\hat{\gamma}_{1, t}=\alpha_{1}+\eta_{1}\left(R_{m, t}-r_{f}\right)$

Under the null hypothesis $\eta_{1}$ is expected to be equal to one as the series of $\hat{\gamma}_{1}$ 's are theoretically estimates of the market premium.

Table 5 The JSE as a whole

\begin{tabular}{lccc}
\hline Period & $\hat{\eta}_{1}$ & $t\left(\hat{\eta}_{1}\right)$ & $R^{2}$ \\
\hline $1973-80$ & 1,008 & 5,191 & 0.729 \\
$1973-81$ & 0,890 & 2,586 & 0,378 \\
$1974-82$ & 1,028 & 4,122 & 0,607 \\
$1975-83$ & 1,041 & 4,591 & 0,657 \\
$1976-84$ & 0,674 & 1,306 & 0,134 \\
Whole period & 0,988 & 7,986 & 0,507 \\
Test period & & & \\
(1980-84) & & & \\
\hline
\end{tabular}

Table 5 shows the results of these corrected regressions.

From Table 5 all the $\hat{\eta}_{1}$ 's with the exception of period 5 are seen to be very close to unity and highly significant. Over all the testing periods $\hat{\eta}$ was found to be 0,988 with a $t$ statistic of 7,986 . This evidence further supports the validity of the CAPM for the JSE.

The results obtained in this section therefore lead one to conclude that the data from the JSE appear to be consistent with the one-parameter CAPM. In addition, unlike many US studies, the results show that in the JSE context, the 12-month fixed deposit, rate at major commercial banks appears to be a reasonable surrogate for the risk-free rate.

\section{The gold share market on the JSE}

The above tests were again repeated using all $\mathbf{4 5}$ gold shares available over the same period. The resulting coefficients of the time series of $\hat{\gamma}_{1}$ 's on the market premium obtained from (4) will be shown in Table 6. The average of the coefficients corrected by their hypothesized values and their associated $t$ statistics for each period are tabulated in the Appendix (Table A1).

The tests were repeated using the JSE Actuaries AllGold Index as well as the JSE Actuaries Overall Index and the results are summarized in Table 6 .

The results using the All-Gold Index are essentially the same as those obtained using the Overall Index. However, they differ substantially from the results obtained for common stocks. In both cases the $\hat{\eta}_{1}$ 's are not as close to one as was the case for common stocks, and suprisingly, even negative $\hat{\eta}_{1}$ coefficients are evident. In fact in only one of the periods (i.e. 1983 for the All-Gold Index) was the $\hat{\eta}_{1}$ significantly different from zero. It thus appears as if the related market risk, i.e. $\beta$, has not been highly correlated with return for gold shares. This finding may be due to the fact that gold shares are not priced predominantly by local investors but by foreign investors in the SA gold market.

In order to ascertain whether the influence of USA investment in gold shares is in line with the CAPM when expressed in dollar returns, the study was repeated converting gold share prices and the relevant indices to

Table 6 Gold shares - rand returns

\begin{tabular}{lrrrc}
\hline & Period & \multicolumn{1}{c}{$\hat{\eta}_{1}$} & $t\left(\dot{\eta}_{1}\right)$ & $R^{2}$ \\
\hline All-Gold Index & $1973-80$ & 0,133 & 0,829 & 0,059 \\
& $1973-81$ & 0,491 & 1,124 & 0,103 \\
& $1974-82$ & -0.278 & $-1,106$ & 0.100 \\
& $1975-83$ & 0,754 & 3,214 & 0.484 \\
Overall Index & $1976-84$ & 0.517 & 1,374 & 0,147 \\
& $1973-80$ & 0.344 & 1,431 & 0,157 \\
& $1973-81$ & 0,833 & 1,792 & 0.226 \\
& $1974-82$ & -0.451 & $-1,073$ & 0,095 \\
& $1975-83$ & 0.638 & 1,676 & 0,203 \\
& $1976-84$ & $-0,110$ & $-0,247$ & 0,005 \\
\hline
\end{tabular}


Table 7 Gold shares - dollar returns

\begin{tabular}{lcccc}
\hline & Period & $\hat{\eta}_{\mathbf{1}}$ & $t\left(\hat{\eta}_{1}\right)$ & $R^{2}$ \\
\hline All-Gold Index & $1973-80$ & 0,223 & 0,223 & 0,126 \\
& $1973-81$ & 0,680 & 2,266 & 0,318 \\
& $1974-82$ & 0,091 & 0,297 & 0,008 \\
& $1975-83$ & 0,671 & 4,253 & 0,622 \\
& $1976-84$ & 0.536 & 2,027 & 0,272 \\
& $1973-80$ & 0,248 & 0,817 & 0,057 \\
& $1973-81$ & 0,765 & 1,226 & 0,120 \\
& $1974-82$ & 0,316 & 0,883 & 0,066 \\
& $1975-83$ & 0,801 & 4,276 & 0,624 \\
& $1976-84$ & 0,644 & 2,547 & 0,371 \\
\hline
\end{tabular}

dollars. (Adjustments were made for the Financial Rand and Securities Rand discount when applicable.)

Results of the cross-sectional regressions using (4) with dollar return estimates are shown in Table 7 ( Table A2 in the Appendix contains the details relating to the cross-sectional regressions.)

Comparing Table 7 (dollar return statistics) with Table 6 (rand return statistics) it is evident that the $\hat{\eta}_{1}$ are now closer to the theoretical value of unity with higher $t$ statistics than those obtained using rand returns. The results obtained using both indices are again essentially similar. The hypothesis that $\eta_{1}$ is equal to one (i.e. that the one-parameter CAPM is valid) is only rejected for the 1980 and 1982 testing periods for both indices. It is interesting to note that these two years represent the major bull and bear phases of the gold share market respectively, with the gold price reaching $\$ 800$ an ounce in the 1980 testing period while plummeting to a low of $\$ 296$ an ounce in June during the 1982 testing period. It is thus evident that during these extreme periods the dollar pricing of gold shares were not consistent with the ex ante beta predictors.

Comparing these results to the results obtained for common stocks (Table 5 ) it can be seen that although there is a marked improvement when returns are measured in dollar terms the results nevertheless indicate that the CAPM is a more appropriate model for common stocks in the JSE context than for gold shares.

The relative weakness of the CAPM in the case of gold stocks may, as mentioned earlier, revolve around the large foreign holding of gold shares. During the period under consideration several exchange rate regimes have been operative and the exchange rate itself has been volatile. These problems have given rise to risk factors for foreign holders of gold shares over and above those faced by local investors and have been instrumental in the instability of the risk assessment of SA gold shares by foreigners.

\section{Dividend yield}

The empirical test for a dividend yield effect was based on estimating the $\gamma$ 's from cross-sectional regressions using (2) as is explained in the section headed 'Methodology'. The ex-ante dividend yield measures
Table 8 Dividend yield effects - JSE as a whole

\begin{tabular}{lcc}
\hline Period & $\hat{\alpha}_{2}$ & $t\left(\dot{\alpha}_{2}\right)$ \\
\hline $1973-81$ & $-0,0174$ & $-1,011$ \\
$1974-82$ & 0,0048 & 1,265 \\
$1975-83$ & 0,0028 & 0,275 \\
$1976-84$ & 0,0031 & 0,417 \\
Whole period & $-0,0004$ & $-0,043$ \\
\hline
\end{tabular}

were taken to be the total dividends per share paid during the previous year divided by the share price at the end of that year. Estimates of the dividend yield of a portfolio (i.e. $\hat{\delta}_{p, t-1}$ ) were computed as the average dividend yield of the component securities. Estimates of the dividend yield of the market, i.e. $\hat{\delta}_{m, t-1}$ were similarly computed.

\section{The JSE as a whole}

The systematic sample of 100 stocks was used to test the dividend yield effect. The average of the $\hat{\gamma}_{2}$ 's and the associated statistics obtained from the 13 cross-sectional regressions (2) in each testing period are shown in Table A 3 in the Appendix.

The final estimates of the $\gamma_{2}$ 's, i.e. the $\hat{\alpha}_{2}$ 's obtained from the time series regression of the $\gamma_{2}$ 's on the market premium in equation (3) are shown in Table 8.

The results shown in Table 8 can be compared directly to the results obtained by Black \& Scholes (1974) on the NYSE as shown in Table 1 . The results obtained here are almost identical in magnitude and spirit to the results obtained by Black \& Scholes (1974). The column of $\hat{\alpha}_{2}$ 's indicates that the dividend yield effect and none of $t$ statistics of the $\hat{\alpha}_{2}$ 's are significantly different from zero. This implies that the expected returns on high dividend yield securities are not significantly different from the expected returns on low dividend yield securities on the JSE, other things being equal. For the whole period the $\hat{\alpha}_{2}$ is equal to $-0,0004$, which is approximately $0,5 \%$ per year, which is nowhere near the level that would make the tax penalty significant. By comparison Black \& Scholes (1974) obtained a value of 0,0009 for $\hat{\alpha}_{2}$ with a $t$ statistic value of 0,94 over their entire period of study on the NYSE. In addition the emergence of some negative estimates of $\hat{\alpha}_{2}$ in Table 8 does not make these inferences any different from the inferences of Black \& Scholes on the NYSE.

The implication of these findings for the JSE investor are that higher yielding shares have not had their prices bid down to reflect higher expected returns in compensation for the tax penalty on dividends. In other words the expected returns of high-yielding stocks on the JSE are not essentially different from those of lowyielding stocks for the same level of risk.

\section{The gold share market on the JSE}

The tests were repeated on all gold shares having a complete record of the relevant information over the 
Table 9 Dividend yield effects - Gold shares

\begin{tabular}{lcc}
\hline Period & $\hat{\mathbf{x}}_{2}$ & $t\left(\hat{\alpha}_{2}\right)$ \\
\hline $1973-81$ & $-0,0135$ & $-0,807$ \\
$1974-82$ & $-0,0099$ & $-0,550$ \\
$1975-83$ & $-0,0260$ & $-1,291$ \\
$1976-84$ & $-0,0102$ & $-1,484$ \\
Whole period & $-0,0100$ & $-1,010$ \\
\hline
\end{tabular}

1973-1984 period. This amounted to 39 shares. Owing to the small sample only nine intermediate portfolios were formed. This involved grouping the securities into three portfolios on the basis of their ranked dividend yield and dividing each of these portfolios into a further three portfolios on the basis of their ranked betas. The average $\hat{\gamma}_{2}$ 's obtained from the 13 cross-sectional regressions in each testing period are shown with their relevant statistics in the appendix (Table A3).

The final estimates of the dividend yield effect, i.e. the $\hat{\alpha}_{2}$ 's obtained from (3) are shown in Table 9.

All of the $\hat{\alpha}_{2}$ 's in Table 9 are negative but not significant at the $5 \%$ level of significance. The fact that the $\hat{\alpha}_{2}$ 's are consistently negative implies that gold shares having high dividend yields have lower expected returns than low-yielding gold shares with the same level of risk. This would be consistent with the hypothesis that investors prefer high-yielding gold shares. Thus, although these effects are not significant at the $5 \%$ level the results do suggest that there may be a slight preference for high dividend yielding stocks in the gold sector of the JSE.

The problem of unstable $\beta$ 's and the poor performance of $\beta$ 's as predictors of return for gold shares has already been cited. It is possible that other components of gold mine risk which are not captured by the $\beta$ 's may be partly manifested in the dividend yield effect. Perhaps factors such the life of the mine, grade of ore or the working costs are related to dividend payouts. Consequently investors may be paying more for certain stocks in order to avoid these possible components of risk which may not have been fully captured by the shares $\beta$ and this is manifesting itself as a small dividend effect. Furthermore the fact that the US investors did not have to take dividends out of SA through the financial rand when it was operable could well have caused US investors to migrate towards higher yielding gold shares.

In summary, from the empirical evidence it must be concluded that there does not appear to be a significant dividend yield effect on the JSE. Thus it does not appear that, on average, either high-yielding or low-yielding stocks trade at a premium. However, in the case of the gold shares it is possible that a slight preference for highyielding stocks may exist. Whether this is because of confounding factors such as specific mine characteristics and exchange rate policy or because of a genuine preference for high-yield gold stocks, remain an open question.

\section{Market capitilization (size)}

The method used for calculating the ex-ante measures of size was the same as that used by Banz (1981), that is, the stock price multiplied by the number of shares outstanding at the end of the period. The estimates of the size of the portfolios were computed as the average of the size of all component securities (i.e. $\hat{\boldsymbol{\delta}}_{p ; t-1}$ ) and the size of the market $\left(\hat{\delta}_{m ; t-1}\right)$ was similarly calculated.

\section{The JSE as a whole}

The data used here were again the systematic sample of 100 JSE stocks. The 13 cross-sectional regressions using (2) were again run in each testing period using the series of portfolio estimates of $\beta$ and $\delta$ as discussed in the methodology section.

The resulting average $\hat{\gamma}_{2}$ 's are shown in the Appendix (Table A4). Again the final estimators of the $\gamma_{2}$ 's, i.e. the $\hat{\alpha}_{2}$ 's are obtained by running the usual regression correction using (3). The results are shown in Table 10.

Table 10 shows a negative value for size effect $\left(\hat{\alpha}_{2}\right)$ over the whole period - but it is not statistically significant. Further no consistency in sign nor any significant $t$ statistics for $\hat{\alpha}_{2}$ can be found for any of the sub-periods. This implies that there is no small firm effect on the JSE. In other words investors on the JSE apparently do not pay more for large firms than for small firms given the same level of risk.

In contrast studies on the NYSE have found a small but significant negative size effect for NYSE stocks. The widely quoted paper by Banz (1981) for example documents a value of $-0,00052$ with a $t$ value of $-2,92$ for $\hat{\alpha}_{2}$ for the 1936-1975 period (see Table 1). Although not all of the sub-periods have significant $\hat{\alpha}_{2}$ 's they are consistently negative in sign. As was mentioned previously, the issue of whether size per se or some anomaly related to size is responsible for this effect on the NYSE has not yet been resolved.

\section{The gold share market on the JSE}

The same testing procedure was repeated for the gold shares. The details of the cross-sectional regressions are shown in the Appendix (Table A4).

Table 11 shows the final estimators of the 'size' effect, i.e. the $\hat{\alpha}_{2}$ 's obtained from the regression correction (3).

From inspection of Table 11 above it can be seen that there is clearly no evidence of a size effect measured by the $\hat{\alpha}_{2}$ 's for gold shares. Indeed, if anything, the $t$ statistics are smaller for the gold shares as a group than

Table 10 Size effects - JSE as a whole

\begin{tabular}{lrr}
\hline Period & \multicolumn{1}{c}{$\hat{\alpha}_{2}$} & \multicolumn{1}{c}{$t\left(\hat{\alpha}_{2}\right)$} \\
\hline $1973-81$ & $-0,0083$ & $-1,200$ \\
$1974-82$ & 0,0028 & 0.936 \\
$1975-83$ & $-0,0026$ & $-1,695$ \\
$1976-84$ & 0,0032 & 1,109 \\
Whole period & $-0,0017$ & $-0,169$ \\
\hline
\end{tabular}


Table 11 Size effects - Gold shares

\begin{tabular}{lrr}
\hline Period & \multicolumn{1}{c}{$\hat{\alpha}_{2}$} & $t\left(\dot{\alpha}_{2}\right)$ \\
\hline $1973-81$ & $-0,0020$ & $-0,334$ \\
$1974-82$ & 0,0004 & 0,073 \\
$1975-83$ & 0,0010 & 0,126 \\
$1976-84$ & 0,0021 & 0,696 \\
Whole period & $-0,0010$ & $-0,122$ \\
\hline
\end{tabular}

for the overall sample representing the JSE as a whole.

Thus it is concluded that, unlike the The NYSE, there does not appear to be a significant size effect on the JSE. This is true for both the overall market and the gold sector.

\section{Liquidity}

The problem of finding a suitable computational measure of liquidity that does not reflect the arrival of new information was previously cited and the bid-ask spread was suggested as being a suitable measure. Unfortunately accurate records of bid-ask spreads of listed shares are rarely found and such spreads are not quoted in many non-specialist markets such as the JSE. Roll (1984) has proposed a method for estimating an implicit bid-ask spread directly from the time series of share prices. Roll shows that the percentage bid-ask spread can be estimated from the covariance of succesive returns as follows

$$
\text { Spread } \%=200 \sqrt{-\operatorname{Cov}\left(r_{t} ; r_{t-1}\right)}
$$

where $r_{t}$ is the return of the share at time $t$.

The assumptions necessary for the derivation of (5) are:

(i) the asset is traded in an informationally efficient market; and (ii) the probability distribution of observed price changes is stationary.

Unfortunately bid-ask spread data are not available for JSE stocks and hence the accuracy of Roll's proposed estimator cannot be assessed in this context. However Amihud \& Mendelson (1986) report a correlation of 0,242 between the average return and the logarithm of spread on the NYSE over the 1961-1980 period. By comparison we find a similar correlation of 0,2408 between the average return and the average estimate of spread using (5) for 50 gold shares on the JSE over the 1972-1984 period ${ }^{4}$. This at least indicates that Roll's formula may provide a reasonable estimate of the bidask spread implicit in JSE stocks.

Roll's formula for estimating the bid-ask spread was thus used as a proxy for the liquidity effect $(\delta)$ in this study. The time series of returns over the formation period and again over the estimation were used to obtained the ex-ante estimates of spread. The estimate of a portfolio's spread $\delta_{p}$ was taken to be the average spread of its components. The spread of the market, $\delta_{m}$, was taken to be the average spread of all shares in the sample.
Table 12 Liquidity effects - JSE as a whole

\begin{tabular}{lcc}
\hline Period & $\hat{\alpha}_{2}$ & $t\left(\hat{\alpha}_{2}\right)$ \\
\hline $1973-80$ & $-0,005$ & $-0,461$ \\
$1973-81$ & $-0,001$ & $-0,110$ \\
$1974-82$ & $-0,023$ & $-1,551$ \\
$1975-83$ & $-0,009$ & $-0,757$ \\
$1976-84$ & 0,006 & 0,526 \\
Whole period & $-0,005$ & $-1,121$ \\
\hline
\end{tabular}

\section{The JSE as a whole}

Again the same testing procedure was repeated here using the sample of 100 JSE stocks. The results of the cross-sectional regressions using (2) are shown in the Appendix (Table A5). The final estimators of the liquidity effects, i.e. the $\hat{\alpha}_{2}$ 's obtained from (3) for each test period are shown in Table 12.

None of the $\hat{\alpha}_{2}$ 's in Table 12 are seen to be significant. Thus it must be concluded that there is insufficient statistical evidence to infer any liquidity effect on the JSE as a whole.

By contrast Amihud \& Mendelson (1986) found significant evidence that the spread effect is positively related to stock return. Their study was conducted over the 1961-1980 period on the NYSE actual bid-ask spread data. They obtain a value of 0,00375 with $t$ statistic of 3,23 for the spread effect. This implies that returns on high spread (illiquid) stocks are higher than returns on low-spread (liquid) stocks. It is interesting to note that in four of the five periods examined on the JSE the sign of $\hat{\alpha}_{2}$ was negative, implying that any liquidity effect present was in fact in the opposite direction to that found in the Amihud \& Mendelson study. This is counter intuitive and hence we can only conclude that either no liquidity effect exists on the JSE or that the bid-ask spread measure proposed by Roll (1984) does not measure the true implicit bid-ask spread on the JSE with sufficient accuracy to detect the effect.

Table 13 Liquidity effects - Gold shares

\begin{tabular}{lrrr}
\hline & \multicolumn{1}{c}{ Period } & \multicolumn{1}{c}{$\hat{\alpha}_{2}$} & \multicolumn{1}{c}{$t\left(\hat{\alpha}_{2}\right)$} \\
\hline All-Gold Index & $1973-80$ & $-0,005$ & $-0,430$ \\
& $1973-81$ & $-0,007$ & $-0,433$ \\
& $1974-82$ & 0,022 & 0,706 \\
& $1975-83$ & 0,009 & 0,485 \\
Overall Index & $1976-84$ & $-0,001$ & -0.032 \\
& $1973-80$ & $-0,009$ & $-0,847$ \\
& $1973-81$ & $-0,021$ & $-1,493$ \\
& $1974-82$ & 0,043 & 1,211 \\
& $1975-83$ & 0,003 & 0.186 \\
& $1976-84$ & $-0,002$ & $-0,193$
\end{tabular}




\section{The gold share market on the JSE}

The above testing procedures was again repeated for the complete set of $\mathbf{4 5}$ gold shares. Here 12 portfolios were constructed by dividing the shares into four groups on the basis of their ranked bid-ask spread estimates whereafter each group was furhther divided into three portfolios on the basis of their ranked $\beta$ 's. This procedure was repeated using both the All-Gold Index and the Overall Index. Table A5 in the Appendix cointains details of the correction on the time series of $\hat{\gamma}_{2}$ 's using (3).

Again the $\hat{\alpha}_{2}$ 's in Table 13 show no systematic nor significant statistical behaviour. This is consistent with the results obtained using the sample of 100 stocks and hence the overall conclusion of this section is that a liquidity effect does not exist on the JSE.

\section{Conclusion}

The results of our analysis based on traditional testing procedures have several implications for the investor on the JSE. In particular our results imply that the oneparameter CAPM appears to be a reasonable model for the JSE as a whole. This implies that ex-ante estimates of $\beta$ are succesful in systematically predicting stock returns on the JSE given the level of market premium and the risk-free rate.

For gold shares, $\beta$ 's do not enjoy the same level of success as predictors of return. This could be due to the interactive pricing of gold shares by both local SA investors and foreign investors who are exposed to different risk factors. Our results show a marked improvement in the predictability of $\beta$ when assessed in dollar terms. This tends to imply that US investors may have been dominant over local investors in the pricing of gold shares over the 1973-1984 period. It is expected that this situation will change owing to the subsequent (November 1986) restriction of US investment in South Africa. It will of course be interesting to monitor to what extent $\beta$ 's will improve as predictors of Rand returns (that is, from the South African investor's viewpoint) owing to this restriction.

Secondly our evidence on the dividend yield effect for the JSE as a whole does not show any significant differences between the returns on high dividend yield stocks and the returns on low dividend yield stocks. In the analysis no account was taken of tax on dividends or capital gains. Hence the implications are that a taxexempt investor may not gain significantly by selecting high yield stocks over low yield stocks, other things being equal. The implication for corporations is that a change in dividend policy will not be expected to have a definitive effect on its stock price. For gold shares there may be some evidence of a slight systematic shift towards a negative dividend yield effect on expected returns. This implies that investors may have a slight preference for high-yielding gold shares. However, this effect is not statistically significant. A plausible reason for such an effect could be that foreign investors do not have dividend payouts diluted by the financial rand discount while capital gains on the other hand are diluted by the financial rand. This may well induce foreign investors (especially short-term investors) to have a preference for high-yielding gold shares. Again this effect is likely to change due to the subsequent restriction on SA gold share purchases.

The size or market capitilization effect documented on the NYSE does not appear to exist on the JSE either for industrial or for gold stocks. This implies that investors cannot expect to earn consistently higher risk-adjusted returns by tilting their portfolios either towards small or large firms.

Lastly the liquidity effect measured by a proposed estimate of bid-ask spread was not found to have any significant effect on returns of industrial and goid shares on the JSE. Intuitively this result was expected for gold shares which are highly liquid. It should be noted however, that it is not clear whether the results for the JSE as a whole were insignificant owing to the abscence of a liquidity effect or whether the proposed measure of estimating the bid-ask spread was inaccurate.

In conclusion the one parameter CAPM has stood up well to traditional empirical testing. Moreover hypothesized additional parameters, namely; dividend yield, market capitilization and liquidity were not found to significantly effect return. Consequently the CAPM is accepted as a reasonable model in the context of the JSE.

\section{Notes}

1. While Roll's comments are indeed relevant, it is worth noting that failure to reject will still imply consistency with the CAPM (and of course the market surrogate)

2. Owing to the smaller number of gold shares available only 12 portfolios were constructed for testing the gold share market separately, i.e. the additional factor was ranked and divided into four groups whereafter each group was subdivided into three portfolios on the basis of their ranked betas.

3. The $\boldsymbol{t}$ statistics shown in Table $\mathbf{4}$ are calculated using

$\mathrm{t}\left(\overline{\left.\hat{\gamma}_{j}-r\right)}=\frac{\overline{\hat{\gamma}_{j}-r}}{S\left(\hat{\gamma}_{j}-r\right)} / \sqrt{n}\right.$

where $r$ is equal to $r_{f}$ in column 2 and $R_{f}-r_{f}$ in column 3 . Column 6 shows the average $R^{2}$ of the 13 cross-sectional regressions in each testing period.

4. Roll (1984) further finds cvidence that the estimated bidask spread is related to firm size. He documents a rank correlation of $-0,226$ between estimated bid-ask spread and size taken at five-day intervals on the NYSE. We find an average annual Kendall's rank correlation over the period 1971-1984 of $-0,2323$ for gold shares taken at weekly intervals on the JSE.

\section{References}

Amihud, Y. \& Mendelson, H. 1986. Liquidity and Stock Returns. Fin. Anal. J., 43-48.

Banz, R.W. 1981. The relationship between Return and Market Value of Common Stock. J. Fin. Econ., 3-18. 
Basu,S. 1977. Investment performance of common stocks in relation to their price-earnings ratios: $A$ test of market efficiency. J. Fin., vol.32, 663-682.

Black, F., Jensen, M.C. \& Scholes, M. 1972. The capital asset pricing model: Some empirical tests. In: Studies in the theory of capital markets. Ed. Jensen, .C., Praeger, New York, 79-124.

Black, F. \& Scholes, M. 1974. The Effects of Dividend Yield and Dividend Policy on Common Stock Prices and Returns. J. Fin. Econ., vol. 1, 1-22.

Blume, M.E. \& Friend, I. 1973. A new look at the capital asset pricing model. J. Fin., vol.28, 19-34.

Blume, M.E. \& Stambaugh, R.F. 1983. Biases in Computed Returns: An Application to the Size Effect. J. Fin Econ., 371-386.

Brennan. M.J. 1970. Taxes, Market Valuation and Corporation Financial Policy. Nat. Tax J., 417-427.

Chi-Cheng, H., Reilly, F.K. \& Wong, G.W. 1985. Comparative Liquidity of Capital Assets: An Empirical Study. Working Paper, Univ. of Notre Dame.

Fama, E.F. \& Macbeth, J.D. 1973. Risk, return and equilibrium: Empirical tests. J. Pol. Econ., vol.81, 607-636.

Gordon, R.H. \& Bradford, D.F. 1980. Taxation and the Stock Market Valuation of Capital Gains and Dividends: Theory and Empirical Results. J. Public Econ., vol.14, 109-136.

Jacob, N.L. \& Pettit, R.R. 1984. Investments. Richard D. Irwin, Inc. Homewood Illinois, 973p

Keim, D.B. 1985. Dividend Yields and Stock Returns: Implications of Abnormal January Returns. J. Fin. Econ., 473-489.

Lintner, J. 1965. The valuation of risk assets and the selecton of risky investments in stock portfolios and capital budgets. Rev. Econ. Stat., vol.47, 13-47.

Litzenberger, R.H. \& Ramaswamy, K. 1979. The effect of Personal Taxes and Dividends on Capital Asset Prices: Theory and Empirical Evidence. J. Fin. Econ., vol.7, 163-195.

Litzenberger, R.H. \& Ramaswamy, K. 1980. Dividends, Short Selling Restrictions, Tax-induced Investor Clienteles and Market Equilibrium. J. Fin., vol. 35, 469-482.

Litzenberger, R.H. \& Ramaswamy, K. 1982. The Effects of Dividends on Common Stock Prices: Tax Effects or
Information Effects? J. Fin., 429-443.

Long, J.B. 1978. The Market Valuation of Cash Dividends: A Case to Consider. J. Fin. Econ., vol. 6, 235-264.

Markowitz, H. 1952. Portfolio Selection. J. Fin., vol.7, 77-91.

Mayers, D. 1972. Non-marketable Assets and the Capital Market Equilibrium under Uncertainty. Reprinted in:

Studies in the Theory of capital Markets. Ed. Jensen, M.C., Praeger, New York, 223-248.

Merton, R. 1973. An Intemporal Capital Asset Pricing Model. Econometrica, 867-888.

Miller, M.H. \& Scholes, M.S. 1978. Dividends and Taxes. J. Fin. Econ., vol.6, 333-364.

Miller, M.H. \& Scholes, M.S. 1982. Dividends and Taxes: Some Empirical Evidence. J. Pol. Econ., vol.90, 1118-1141.

Mossin, J. 1966. Equilibrium in a Capital Asset Market. Econometrics, vol.34, 768-783.

Reinganum, M.R. 1981. Misspecification of Capital Asset Pricing: Empirical Anomalies based on Earnings Yields and Market Values. J. Fin. Econ., vol. 9, 19-46.

Reinganum, M.R. 1983. The Anomalous Stock Market Behaviour of Small Firms in January: Empirical Tests for Tax-Loss Selling Effects. J. Fin. Econ., 89-104.

Roll, R. 1977. A critique of the Asset Pricing Theory's Tests. J. Fin. Econ., March, 129-176.

Roll, R. 1984. A Simple Implicit Measure of the Effective Bid-Ask Spread in an Efficient Market. J. Fin., vol.39, 1127-1139.

Rosenberg, B. \& Marathé, V. 1979. Tests of capital asset pricing hypothesis. Res. Fin., vol.1, 115-223.

Sharpe, W.F. 1964. Capital asset prices: A theory of market equilibrium under conditions of risk. J. Fin., vol.19, $425-442$.

Stambaugh, R. 1982. On the exclusion of Assets from the Two-Parameter Model: A Sensitivity Analysis. J. Fin. Econ., 237-268.

Stone, B.K. \& Bartter, B. 1979. The Effect of Dividend Yield on Stock Returns: Empirical Evidence on th Relevance of Dividends. Working Paper No. E-76-8, Atlanta, Ga.: Georgia Inst. Tech.

Tinic, S.M. 1972. The Economics of Liquidity Services. Quart. J. Econ., vol.86, 79-93.

\section{Appendix}

Table A1 Goid shares (rand returns) - corrected regression coefficients obtained from Equation 2

\begin{tabular}{lccccc}
\hline & Period & $\overline{\hat{\gamma}_{0}-r_{f}}$ & $t \overline{\left(\hat{\gamma}_{0}-r_{f}\right)}$ & $\overline{\hat{\gamma}_{1}-\left(R_{m}-r_{f}\right)}$ & $t\left(\overline{\hat{\gamma}_{1}-\left(R_{m}-r_{f}\right)}\right)$ \\
\hline All-Gold Index & $1973-80$ & 0,0478 & 1,442 & $-0,0453$ & $-1,659$ \\
& $1973-81$ & $-0,0360$ & $-1,134$ & 0,0321 & 0,998 \\
& $1974-82$ & 0,0464 & 0,623 & $-0,0348$ & $-0,577$ \\
& $1975-83$ & 0,0136 & 0,373 & $-0,0081$ & $-0,258$ \\
Overall Index & $1976-84$ & 0,0199 & 0,603 & $-0,0246$ & 0,771 \\
& $1973-80$ & 0,0230 & 0,861 & $-0,0148$ & $-0,770$ \\
& $1973-81$ & $-0,0549$ & $-2,658$ & 0,0342 & 1,701 \\
& $1974-82$ & 0,0567 & 0,569 & $-0,0131$ & $-0,232$ \\
& $1975-83$ & $-0,0429$ & $-0,842$ & 0,0244 & 0,773 \\
\hline
\end{tabular}


Table A2 Gold shares (dollar returns) - corrected regression coefficients obtained from Equation 2

\begin{tabular}{lccccc}
\hline & Period & $\overline{\hat{\gamma}_{0}-r_{f}}$ & $t \overline{\left(\overline{\hat{\gamma}_{0}-r_{f}}\right)}$ & $\overline{\hat{\gamma}_{1} \cdot\left(R_{m}-r_{f}\right)}$ & $t\left(\overline{\hat{\gamma}_{1}-\left(R_{m}-r_{f}\right)}\right)$ \\
\hline All-Gold Index & $1973-80$ & 0,0455 & 1,293 & $-0,0416$ & $-1,307$ \\
& $1973-81$ & $-0,0243$ & $-1,232$ & 0,0217 & 0,957 \\
& $1974-82$ & 0,0388 & 0,532 & $-0,0283$ & $-0,481$ \\
& $1975-83$ & 0,0087 & 0,343 & $-0,0037$ & $-0,164$ \\
& $1976-84$ & $-0,0183$ & $-0,516$ & 0,0136 & 0,419 \\
& $1973-80$ & 0,0024 & 0,059 & 0,0026 & 0,081 \\
& $1973-81$ & $-0,0820$ & $-2,027$ & 0,0498 & 1,533 \\
& $1974-82$ & 0,0271 & 0,400 & 0,0068 & 0,158 \\
& $1975-83$ & $-0,0169$ & $-0,658$ & 0,0069 & 0,404 \\
& $1976-84$ & $-0,0386$ & $-1,142$ & 0,0411 & 1,823 \\
\hline
\end{tabular}

Table A3 Average $\hat{\gamma}_{2}$ coefficient measuring the dividend yield effect

\begin{tabular}{lcccc}
\hline & \multicolumn{2}{c}{ The JSE as a whole } & \multicolumn{2}{c}{ Gold shares } \\
\cline { 2 - 5 } Period & $\hat{\gamma}_{2}$ & $t\left(\hat{\gamma}_{2}\right)$ & $\hat{\gamma}_{2}$ & $t\left(\hat{\gamma}_{2}\right)$ \\
\hline $1973-81$ & $-0,1543$ & $-0,9608$ & $-0,0075$ & $-0,448$ \\
$1974-82$ & 0,0048 & 1,3346 & $-0,0121$ & $-0,557$ \\
$1975-83$ & 0,0021 & 0,1953 & $-0,0296$ & $-1,198$ \\
$1976-84$ & 0,4057 & 0,4507 & $-0,0101$ & $-1,525$ \\
\hline
\end{tabular}

Table A4 Average $\hat{\gamma}_{2}$ coefficient measuring the firm size effect

\begin{tabular}{lrrrr}
\hline & \multicolumn{2}{c}{ The JSE as a whole } & \multicolumn{2}{c}{ Gold shares } \\
\cline { 2 - 5 } Period & \multicolumn{1}{c}{$\hat{\gamma}_{2}$} & \multicolumn{1}{c}{$t\left(\hat{\gamma}_{2}\right)$} & \multicolumn{1}{c}{$\hat{\gamma}_{2}$} & $t\left(\hat{\gamma}_{2}\right)$ \\
\hline $1973-81$ & $-0,0076$ & $-1,180$ & 0,0040 & 0,063 \\
$1974-82$ & 0,0030 & 1,010 & $-0,0001$ & $-0,011$ \\
$1975-83$ & $-0,0025$ & $-1,426$ & 0,0002 & 0,208 \\
$1976-84$ & 0,0026 & 0,806 & 0,0023 & 0,779 \\
\hline
\end{tabular}

Table A5 Average $\hat{\gamma}_{2}$ coefficient measuring the liquidity effect

\begin{tabular}{lcccccc}
\hline & & & \multicolumn{4}{c}{ Gold shares } \\
\cline { 4 - 7 } & \multirow{2}{*}{ JSE as a whole } & \multicolumn{2}{c}{ All-Gold Index } & \multicolumn{2}{c}{ Overall Index } \\
\cline { 2 - 7 } Period & $\hat{\gamma}_{2}$ & $t\left(\hat{\gamma}_{2}\right)$ & $\hat{\gamma}_{2}$ & $t\left(\hat{\gamma}_{2}\right)$ & $\hat{\gamma}_{2}$ & $t\left(\hat{\gamma}_{2}\right)$ \\
\hline $1973-80$ & $-0,0067$ & $-0,733$ & $-0,0042$ & $-0,397$ & $-0,0104$ & $-0,959$ \\
$1973-81$ & $-0,0016$ & $-0,214$ & $-0,0083$ & $-0,584$ & $-0,0191$ & $-1,468$ \\
$1974-82$ & $-0,0190$ & $-1,439$ & 0,0378 & 1,085 & 0,0489 & 1,057 \\
$1975-83$ & $-0,0117$ & $-1,088$ & 0,0085 & 0,507 & 0,0048 & 0,286 \\
$1976-84$ & 0,0069 & 0,567 & $-0,0020$ & $-0,117$ & $-0,0013$ & $-0,107$ \\
\hline
\end{tabular}

